\title{
Premature birth: topics in physiology and pharmacological characteristics
}

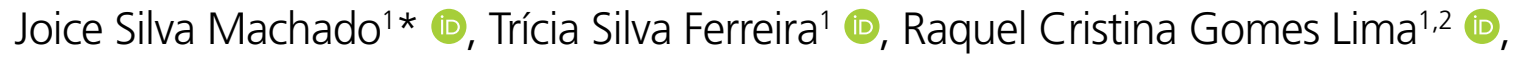 \\ Verônica Cheles Vieira' ${ }^{1,2}$ (D), Danielle Souto de Medeiros ${ }^{1}$
}

\begin{abstract}
SUMMARY
OBJECTIVE: To review the main physiological and pharmacological changes related to prematurity, to promote the evidence-based clinical practice.

METHODS: This is a narrative review whose research was carried out in the ScienceDirect and Medline databases via PubMed, searching for articles in any language from January 2000 to February 2020.

RESULTS: Premature newborns are born before completing the maturation process that prepares them for extrauterine life, which occurs especially in the last weeks of pregnancy. Therefore, they have their own characteristics in development. Several physiological peculiarities stand out, such as disturbances in glucose regulation, adrenal function, thermoregulation, immunity, in addition to changes in liver, renal and respiratory functions. Pharmacological aspects were also highlighted, involving pharmacokinetics and pharmacodynamics. CONCLUSIONS: Despite the recent advances in prematurity, it is still an area with many uncertainties, since several changes occur quickly and there are ethical issues that make studies difficult. Thus, it is clear that the therapeutic management of premature infants is still very much based on clinical practice.

KEYWORDS: Physiology. Pharmacokinetics. Pharmacologic actions. Infant, premature.
\end{abstract}

\section{INTRODUCTION}

Globally, approximately 15 million infants are born prematurely every year ${ }^{1}$. Although the survival rate of preterm infants has risen, prematurity remains responsible for $>60 \%$ of deaths in the first 12 hours postpartum, with the mortality rate lowering with every additional week of pregnancy completed ${ }^{2}$.

Generally, full-term pregnancy follows a specific developmental course such that, before delivery, several maturation changes occur that are specifically designed to aid the fetus throughout its transition from uterine to extrauterine life. Given that premature infants are born before these changes have been completed, they experience difficulties after birth ${ }^{3}$. The physiology of this transition is complex and depends on several factors, including maternal medical history, the status of the placenta, gestational duration, and the presence of fetal anomalies ${ }^{4}$.

All of these physiological considerations can directly interfere with the pharmacokinetics and pharmacodynamics of several drugs. Given the complex reality of premature newborns, a review of the available literature is warranted to promote evidence-based clinical practice. The methods employed in this review are described in Chart 1.

\section{PHYSIOLOGICAL CHARACTERISTICS}

\section{Thermal regulation}

Body temperature is the result of heat production and elimination mechanisms, and the human body tends to release

\footnotetext{
IInstituto Multidisciplinar em Saúde, Universidade Federal da Bahia - Vitória da Conquista (BA), Brasil.

¿Universidade Estadual do Sudoeste da Bahia - Vitória da Conquista (BA), Brasil.

*Corresponding author: machado.joicesilva@gmail.com

Conflicts of interest: the authors declare there are no conflicts of interest. Funding: none.

Received on August 05, 2020. Accepted on August 20, 2020.
} 
heat easier than it produces it. Importantly, thermal control is dependent on gestational and postnatal age, birth weight, and the clinical conditions of the newborn 5 .

Newborns can lose heat through evaporation, convection, conduction, radiation, or combinations thereof. In the first example, heat loss results from water evaporation from the skin and respiratory tract. Convection is the loss of heat from the body to a colder environment. During conduction, heat dissipates by direct contact into colder solid objects. In the absence of direct contact with a colder object, this process is known as radiation ${ }^{6}$.

The large skin surface area-to-body mass ratio in newborns presents a large area for heat loss. The head may account for as much as $20 \%$ of the infant's total surface area. With greater prematurity, the skin becomes thinner, with fewer tight junctions and a thinner layer of subcutaneous fat. Insulation is thereby compromised and greater evaporative heat loss occurs. The infant responds with non-shivering thermogenesis, a process that involves brown fat metabolism and significant oxygen consumption (up to $25 \%$ of total oxygen consumption). Shivering, which is the major means of heat generation in adults, is gradually acquired over the first year of life ${ }^{7}$.

\section{Glucose regulation}

\section{Hypoglycemia}

The fetus exists in an anabolic state, with high endogenous concentrations of insulin and fetal glycogen, promoting glycogenesis and lipogenesis. After birth, there is an increase in the concentration of glucagon, plasma catecholamines, and cortisol, and a decrease in insulin concentration, thereby promoting glycogenolysis, gluconeogenesis, and lipolysis in order to provide energy to the newborn ${ }^{3}$.

During the transition to extrauterine life, the glucose concentration in healthy newborns lowers in the first hours of life, with blood glucose levels approximating $55-60 \mathrm{mg} / \mathrm{dL}$. It is important to differentiate this normal transient physiological response from disorders that result in persistent or recurrent hypoglycemia, which can lead to neurological sequelae ${ }^{8}$. Hypoglycemia is present in approximately $15 \%$ of infants born at term. Premature infants are at increased developmental risk, mainly due to inadequate storage of glycogen, proteins, and fats, which occurs during the third trimester of pregnancy ${ }^{3}$.

Lipolysis contributes significantly to meet neonatal metabolic demands when glycogen is depleted, either by producing glycerol or ketone bodies. However, lipolysis and ketogenesis are limited in premature infants due to the loss of fat in adipose tissue?.

\section{Hyperglycemia}

Hyperglycemia is prevalent in infants with very low birth weight, especially during the first week of life, with the highest numbers seen in infants who are also growth-restricted or who receive intravenous glucose. Estimates show that up to $\geq 80 \%$ of all infants weighing $<1,500$ g may be affected by hyperglycemia ${ }^{9,10}$. Its etiology involves an inability to inhibit gluconeogenesis, relative insulin resistance (possibly related to elevated growth hormone, cortisol, and catecholamine concentrations), defective proinsulin processing, and delayed secretion. Untreated hyperglycemia can lead to significant complications, including hyperosmolality, osmotic diuresis, dehydration, and possible intracranial bleeding and additive effects on ischemic brain injury ${ }^{9,10}$.

\section{Respiratory function}

The respiratory system undergoes significant structural changes during intrauterine development. The airways are completely formed during the pseudoglandular stage, at around 16 weeks of gestation. Between weeks 16 and 24 (i.e., during the canalicular stage), these conductive structures increase in caliber; between weeks 24 and 36 (i.e., during the saccular stage), the pre-acinar airways grow, the bronchioles develop, and the acini are formed. At around 28 weeks of gestation (i.e., during the saccular pulmonary development phase), the alveoli begin to develop ${ }^{11}$.

The pulmonary surfactant begins to be produced around 34 weeks of gestation. This surfactant reduces the surface tension in the alveoli, allowing them to remain inflated. As such, pulmonary surfactant deficiency or dysfunction can lead to respiratory distress syndrome (RDS), a common disorder in premature infants ${ }^{12}$.

Chart 1. Research strategy and criteria for selecting articles

The review was performed using ScienceDirect and MEDLINE via PubMed. Articles in any language published between January 2000 and February 2020 were considered. Keywords used included "physiology", "pharmacokinetics", "pharmacological actions", and "premature newborn". Thwe list of references within the selected articles were also searched, some of which included publications that could not be retrieved. Ultimately, 32 research and review articles were included. 
Apnea of prematurity is experienced by $85 \%$ of babies born before 34 weeks of gestation; the risk of developing it rises substantially with every additional week of gestation missed. Defined as cessation in breathing with a $>15-20$ sec duration, it is believed to result from immaturity of the central respiratory control mechanisms (e.g., reduced sensitivity to $\mathrm{CO}_{2}$ and hypoxia) and from an exaggerated protective response to laryngeal stimulation, ultimately leading to the interruption of inspiratory activation of the respiratory muscles and closure of the upper airways ${ }^{13}$.

\section{Immune system}

The fetal immune system develops in a sterile and protected environment, therefore requiring antigenic exposure. Immune competence develops during the first three months postpartum ${ }^{14}$.

The complement system is the most important component of innate immunity, and it is likely to contribute to the performance of the adaptive immune system ${ }^{15}$. In healthy, at-term newborns, the complement system is already underdeveloped; this is aggravated in premature infants since the liver is responsible for synthesizing nearly all components of the complement system - except for C7 - though it has a primary function of hematopoiesis between gestational weeks 6 and $22^{16}$. Therefore, premature neonates are the most vulnerable to intracellular pathogens that cause infections in the uterus (intrapartum and postpartum) and that evoke fetal and neonatal innate immune responses ${ }^{14}$. Regulatory $\mathrm{T}$ cell functionality is temporarily reduced in premature infants, which can lead to dysregulation or overactivation of the immune response ${ }^{17}$.

\section{Adrenal function}

The fetal adrenal gland undergoes massive hypertrophy during the last trimester of pregnancy, when the reduction in maternal cortisol stimulates the production of adrenocorticotropic hormone (ACTH). Therefore, the fetus may not produce cortisol before 23 weeks of gestation and normally does not do so until 30 weeks, when higher levels of ACTH stimulate cortical development ${ }^{3}$. Cortisol promotes growth of the intestinal mucosa, production of gastric acid, induction of digestive enzymes, gastrin secretion in the fetal intestine, and participates in renal maturation. Therefore, premature infants have an incomplete response to stress. This diminished response appears to occur mainly at the level of the adrenal gland and is limited to the first two weeks of life (temporary adrenocortical insufficiency in preterm infants). Furthermore, prenatal circumstances, such as maternal glucocorticoid administration, can also negatively affect the baby's adrenal response ${ }^{3,9}$.

\section{Renal function}

Although nephron development begins around gestational week 9 , most nephrogenesis occurs in the third trimester, reaching adult nephron numbers at 36 weeks of gestation. Premature infants may have reduced or abnormal nephrogenesis after birth, and may not reach the same number of nephrons as their full-term peers ${ }^{3}$.

Effective renal plasma flow has been reported to be $-20 \mathrm{~mL} /$ $\min / 1.73 \mathrm{~m}^{2}$ in extremely premature babies, compared to $45 \mathrm{~mL} / \mathrm{min} / 1.73 \mathrm{~m}^{2}$ in babies born after 35 weeks of gestation and $83 \mathrm{~mL} / \mathrm{min} / 1.73 \mathrm{~m}^{2}$ in at-term newborns. This increase in blood flow over time is also associated with a proportionally greater flow to the external cortical region, thereby promoting its development ${ }^{18}$. Due to the limitation of renal blood flow and glomerular filtration rate, newborns - and especially premature infants - have a limited ability to handle fluid overload ${ }^{18}$.

\section{Hepatic function}

The liver is the largest solid organ and is responsible for several critical functions, including metabolism of dietary compounds, regulation of blood glucose levels, production of clotting factors and serum proteins, bile synthesis, and biotransformation of xenobiotics and endogenous metabolic byproducts. In intrauterine life, the fetus depends on the mother's liver function while its own liver develops. Even after birth, the newborn's liver function retains a certain immaturity, but at-term newborns are spared any serious longterm consequences. Preterm infants, however, are susceptible to the consequences of immature liver function, which can include hypoglycemia, hyperbilirubinemia, cholestasis, bleeding, and impaired drug metabolism ${ }^{19}$.

\section{PHARMACOLOGICAL CHARACTERISTICS}

Changes in physiological conditions associated with prematurity reflect changes that directly interfere with the absorption, distribution, metabolism, elimination, or mechanism of action of a given medication.

\section{Pharmacokinetics}

\section{Absorption}

In general, gastrointestinal absorption in preterm infants is compromised due to reductions in gastric acidity, bile 
acid excretion, and gastrointestinal motility ${ }^{20}$. Gastric $\mathrm{pH}$ affects the stability and degree of ionization of weak acids drugs; that is, it reduces the relative amount available for absorption. Thus, these drugs are absorbed more slowly. The compromised function of bile and pancreatic enzymes can reduce the bioavailability of fat-soluble drugs. Drug absorption is dependent on the intestinal mucosa that matures its villi around 20 weeks of gestation ${ }^{21}$. Therefore, in extremely premature infants, there is less surface for absorption due to the reduction of villi and intestinal extension, which are proportionally smaller than in full-term babies.

For the percutaneous route, the weight-to-body surface area ratio reflects the need to decrease the concentration of topical drugs, especially in preterm infants with very low birth weight. The proportion of muscle mass in neonates is lower than in adults; however, there is an increase in the density of skeletal-muscle capillaries, which can compensate for this reduction. Indeed, there is evidence - even in older children - of greater absorption via the percutaneous route for specific drugs ${ }^{22}$.

\section{Distribution}

The human body's composition of water, muscles, and fats changes along with gestational and postnatal age. Extracellular fluid compartments are larger in newborns than in adults. In addition, the percentage of weight attributed to fat is $3 \%$ in premature infants and $12 \%$ in at-term infants ${ }^{23}$. As a result, the volume of distribution and the plasma concentration vary with age. Thus, in premature infants, there is a general increase in volume of water-soluble drugs and a reduction in fat-soluble drugs due to the relative proportion of the body, which has a high proportion of water and a low proportion of $\mathrm{fat}^{24}$.

Additionally, there are age-related changes in the development of plasma proteins, with a downregulation of albumin, total protein, and alpha-1-acid glycoprotein. Lower levels of plasma proteins reduce the ability of plasma protein binding drugs, especially in premature newborn $s^{24}$. Thus, premature infants retain a higher concentration of drugs and experience greater effects of drugs with high protein binding.

\section{Metabolism}

The pathways responsible for metabolism and substance elimination do not mature at the same rate $\mathrm{e}^{25}$. The main route for metabolism is hepatic, in which active metabolites can be formed, yielding therapeutic or toxic results. This process is divided into phases I and II. In phase I, the reactions involve cytochrome $\mathrm{P} 450$ isoenzymes, which begin to be produced as of gestational week 25 , with different maturation times for isoenzymes $^{26}$. For this reason, the possibility of drug interactions during the course of treatment must be considered in premature infants.

Enzymes that catalyze phase II reactions also undergo an age-dependent maturation process. The activity of 5'-diphospho-glucuronosyltransferase (UGT) uridine, which has different isoforms, is downregulated by up to $30 \%$ in the livers of neonates. It remains downregulated until postnatal day 10 and may manifest clinically as unconjugated hyperbilirubinemia ${ }^{27}$.

UGT deficiency also has other implications for certain medications, such as morphine and the antimicrobial chloramphenicol: the inability to conjugate does not render them metabolites inactive, but accumulates them. Chloramphenicol can result in gray baby syndrome, and morphine is more active and thus potentially toxic at otherwise therapeutic levels ${ }^{23}$.

\section{Elimination}

At birth, renal clearance is compromised due to incomplete functional and anatomical development of the kidneys in neonates, which remain underdeveloped until several months postpartum. Thus, in the premature infants, tubular secretion is insufficient, mainly due to poor perfusion ${ }^{28}$. As such, corrected gestational age after birth is a better indicator of glomerular filtration rate (GFR) than is chronological age. Premature infants develop tubular function more slowly in the first weeks of life than do full-term newborns, and maximum GFR is achieved at 48 weeks of corrected gestational age ${ }^{29}$. The GFR is $2-4 \mathrm{~mL} / \mathrm{min}$ in full-term babies and $0.6-0.8 \mathrm{~mL} / \mathrm{min}$ in premature babies ${ }^{21}$.

\section{Pharmacodynamics}

Developmental changes in premature infants affect drug pharmacokinetics and other physiological processes, including the activity of receptors or therapeutic targets that mediate the action and response of the drug (i.e., pharmacodynamics $)^{30}$. Due to their intrinsic vulnerabilities and the associated ethical concerns, pediatric populations are often excluded from biomedical research. The scarcity of studies with newborn populations is made evident by the fact that $40-80 \%$ of drugs used in Neonatal Intensive Care Units are off-label or unlicensed ${ }^{31}$.

Moreover, the first month of life is a time of rapid developmental changes, which limits the generalizability of results from studies on neonates. Furthermore, receptors, transporters, and other enzymes are also subject to ontogenic maturation. Thus, investigating the inter- and intra-individual variability in the various pharmacodynamic responses characteristic of neonates would be insightful ${ }^{32}$. Table 1 summarizes the main pharmacodynamic changes observed in premature infants. 
Table 1. Pharmacodynamic changes in preterm infants.

\begin{tabular}{|c|c|}
\hline Physiological Change & Pharmacodynamic Repercussion \\
\hline Changes in blood flow. & $\begin{array}{l}\text { The minimum alveolar concentration for almost all } \\
\text { vapors is lower in neonates than in infancy. } \\
\text { The amount of drug reaching the brain is reduced. }\end{array}$ \\
\hline Increased volume of distribution and reduced NBD clearance. & Increased sensitivity to the effects of NBD. \\
\hline $\begin{array}{l}\text { Reduction in myelination, spacing } \\
\text { of nodes of Ranvier, and length of nerve exposed. }\end{array}$ & $\begin{array}{c}\text { Amide local anesthetic agents induce } \\
\text { shorter blocking duration and require a higher weight- } \\
\text { scaled dose to achieve similar dermatomal levels when } \\
\text { given by subarachnoid block. }\end{array}$ \\
\hline $\begin{array}{l}\text { Age-dependent expression of intestinal motilin receptors and } \\
\text { modulation of antral contractions. }\end{array}$ & $\begin{array}{c}\text { Prokinetic agents may not be useful in very preterm } \\
\text { infants, partially useful in older preterm infants, and } \\
\text { useful in full-term infants. }\end{array}$ \\
\hline Paucity of bronchial smooth muscle. & Bronchodilators are ineffective. \\
\hline $\begin{array}{l}\text { Cardiac calcium stores in the endoplasmic reticulum are } \\
\text { reduced in the neonatal heart, the exogenous calcium has } \\
\text { greater impact on contractility in this age group. }\end{array}$ & $\begin{array}{l}\text { Calcium channel blocking drugs can cause life- } \\
\text { threatening bradycardia and hypotension. }\end{array}$ \\
\hline $\begin{array}{l}\text { Reduction in contractile structures, innervation, and function } \\
\text { of the adrenergic heart receptor. }\end{array}$ & $\begin{array}{l}\text { Reduced response to vasoactive drugs, decreased ability } \\
\text { to increase contractility and inadequate response to } \\
\text { standard preload handling techniques. }\end{array}$ \\
\hline $\begin{array}{l}\beta \text {-receptor maturation lags behind } \alpha \text {-receptor maturation } \\
\text { during the development of the adrenergic system. }\end{array}$ & $\begin{array}{l}\text { Systemic vasoconstriction is greater than pulmonary } \\
\text { vasoconstriction in neonates given dopamine. }\end{array}$ \\
\hline
\end{tabular}

NBD: neuromuscular blocking drugs from Anderson BJ et al. ${ }^{23}$.

\section{FINAL CONSIDERATIONS}

Developmentally, premature newborns are especially complex, with several associated physiological and pharmacological peculiarities. However, despite recent advances in knowledge about prematurity, it remains an area with many uncertainties due to the ever-changing physiological profile of neonates, with ethical considerations placing further limits on clinical research of this particularly vulnerable population. Therefore, the management of premature babies after birth remains largely based on clinical practice.

\section{AUTHORS" CONTRIBUTIONS}

JSM: Methodology, Writing - Original Draft, Writing - Review \& Editing. TSF: Conceptualization, Writing - Original Draft, Writing - Review \& Editing. RCGL: Project Administration. VCV: Project Administration. DSM: Project Administration, Writing - Original Draft, Writing - Review \& Editing.

\section{REFERENCES}

1. Purisch SE, Gyamfi-Bannerman C. Epidemiology of preterm birth. Semin Perinatol. 2017;41(7):387-91. https://doi.org/10.1053/j. semperi.2017.07.009

2. Patel RM, Kandefer S, Walsh MC, Bell EF, Carlo WA, Laptook AR, et al. Causes and timing of death in extremely premature infants from 2000 through 2011. N Engl J Med. 2015;372(4):331-40. https://doi.org/10.1056/NEJMoa1403489

3. Riviere D, McKinlay CJD, Bloomfield FH. Adaptation for life after birth: a review of neonatal physiology. Anaesth Intens Care Med. 2017;18(2):59-67. https://doi.org/10.1016/j. mpaic.2016.11.008
4. Swanson JR, Sinkin RA. Transition from fetus to newborn Pediatr Clin North Am. 2015;62(2):329-43. https://doi. org/10.1016/j.pcl.2014.11.002

5. Brasil. Ministério da Saúde. Secretaria de Atenção à Saúde. Departamento de Ações Programáticas Estratégicas. Atenção à saúde do recém-nascido: guia para os profissionais de saúde [Internet]. 2nd ed. Atualizada.. Brasília: Ministério da Saúde; 2014. v. 4. [cited on Jun 13, 2020]. Available from: https:// bvsms.saude.gov.br/bvs/publicacoes/atencao_saude_recem_ nascido_v2.pdf 
6. Baumgart $S$, Chandra $S$. Temperature regulation of the premature neonate. In: Gleason CA, Devaskar SU, editors. Avery's diseases of the newborn. 9th ed. Philadelphia: Saunders; 2011. p.357-66.

7. Nakayama DK. Management of the surgical newborn: physiological foundations and practical considerations. J Pediatr Urol. 2010;6(3):232-8. https://doi.org/10.1016/j.jpurol.2010.03.009

8. Stanley CA, Rozance PJ, Thornton PS, De Leon DD, Harris D, Haymond MW, et al. Re-evaluating "transitional neonatal hypoglycemia": mechanism and implications for management. J Pediatr. 2015;166(6):1520-5.e1. https://doi.org/10.1016/j. jpeds.2015.02.045

9. Hyman SJ, Novoa Y, Holzman I. Perinatal endocrinology: common endocrine disorders in the sick and premature newborn. Pediatr Clin North Am. 2011;58(5):1083-98. https:// doi.org/10.1016/j.jpeds.2015.02.045

10. Wassner AJ, Modi BP. Endocrine physiology in the newborn. Semin Pediatr Surg. 2013;22(4):205-10. https://doi. org/10.1053/j.sempedsurg.2013.10.010

11. Friedrich $\mathrm{L}$, Corso $\mathrm{AL}$, Jones $\mathrm{MH}$. Prognóstico pulmonar em prematuros. J Pediatr. 2005;81(1 Supl):S79-88. https://doi. org/10.2223/1306

12. Davis RP, Mychaliska GB. Neonatal pulmonary physiology. Semin Pediatr Surg. 2013;22(4):179-84. https://doi.org/10.1053/j. sempedsurg.2013.10.005

13. Atik A, Harding R, De Matteo R, Kondos-Devcic D, Cheong J, Doyle LW, et al. Caffeine for apnea of prematurity: effects on the developing brain. Neurotoxicology. 2017;58:94-102. https://doi.org/10.1016/j.neuro.2016.11.012

14. Maródi L. Neonatal innate immunity to infectious agents. Infect Immun. 2006;74(4):1999-2006. https://doi.org/10.1128/ IAl.74.4.1999-2006.2006

15. Newnam KM, McGrath JM. Understanding the inflammatory response of the neonate: clinical implications for caregivers in the neonatal intensive care unit. Newborn Infant Nurs Rev. 2010;10(4):165-76. https://doi.org/10.1053/j.nainr.2010.09.004

16. McGreal EP, Hearne K, Spiller OB. Off to a slow start: under-development of the complement system in term newborns is more substantial following premature birth. Immunobiology. 2012;217(2):176-86. https://doi.org/10.1016/j. imbio.2011.07.027

17. Mukhopadhyay D, Weaver L, Tobin R, Henderson S, Beeram $M$, Newell-Rogers $M K$, et al. Intrauterine growth restriction and prematurity influence regulatory $\mathrm{T}$ cell development in newborns. J Pediatr Surg. 2014;49(5):727-32. https://doi. org/10.1016/j.jpedsurg.2014.02.055

18. Sulemanji M, Vakili K. Neonatal renal physiology. Semin Pediatr Surg. 2013;22(4):195-8. https://doi.org/10.1053/j. sempedsurg.2013.10.008

19. Grijalva J, Vakili K. Neonatal liver physiology. Semin Pediatr Surg. 2013;22(4):185-9. https://doi.org/10.1053/j. sempedsurg.2013.10.006
20. Ward RM. Drug disposition in the late preterm ("near-term") newborn. Semin Perinatol. 2006;30(1):48-51. https://doi. org/10.1053/j.semperi.2006.01.013

21. Tayman C, Rayyan M, Allegaert K. Neonatal pharmacology: extensive interindividual variability despite limited size. Pediatr Pharmacol Ther. 2011;16(3):170-84. https://doi. org/10.5863/1551-6776-16.3.170

22. Kearns GL, Abdel-Rahman SM, Alander SW, Blowey DL, Leeder JS, Kauffman RE. Developmental pharmacology: drug disposition, action, and therapy in infants and children. $\mathrm{N}$ Engl J Med. 2003;349(12):1157-67. https://doi.org/10.1056/ NEJMra035092

23. Anderson BJ. Neonatal pharmacology. Anaesth Intens Care Med. 2016;18(2):68-74. https://doi.org/10.1016/j.mpaic.2016.11.007

24. Alcorn J, McNamara PJ. Pharmacokinetics in the newborn. Adv Drug Deliv Rev. 2003;55(5):667-86. https://doi.org/10.1016/ s0169-409x(03)00030-9.

25. Allegaert K, van den Anker JN. Clinical pharmacology in neonates: small size, huge variability. Neonatology. 2014;105(4):344-9. https://doi.org/10.1159/000360648

26. Sumpter A, Anderson BJ. Pediatric pharmacology in the first year of life. Curr Opin Anaesthesiol. 2009;22(4):469-75. https://doi.org/10.1097/aco.0b013e32832bc7ff

27. Gow PJ, Ghabrial H, Smallwood RA, Morgan DJ, Ching MS. Neonatal hepatic drug elimination. Pharmacol Toxicol. 2001;88(1):3-15. https://doi.org/10.1034/j.16000773.2001.088001003.x

28. Matalová P, Urbánek K, Anzenbacher P. Specific features of pharmacokinetics in children. Drug Metab Rev. 2016;48(1):70-9. https://doi.org/10.3109/03602532.2015.1135941

29. Rhodin MM, Anderson BJ, Peters AM, Coulthard MG, Wilkins B, Cole $\mathrm{M}$, et al. Human renal function maturation: a quantitative description using weight and postmenstrual age. Pediatr Nephrol. 2009;24(1):67-76. https://doi.org/10.1007/ s00467-008-0997-5

30. Mulla H. Understanding developmental pharmacodynamics: importance for drug development and clinical practice. Paediatr Drugs. 2010;12(4):223-33. https://doi.org/10.2165/11319220000000000-00000

31. Brasil. Ministério da Saúde. Secretaria de Ciência, Tecnologia e Insumos Estratégicos. Departamento de Assistência Farmacêutica e Insumos Estratégicos. Assistência farmacêutica em pediatria no Brasil: recomendações e estratégias para a ampliação da oferta, do acesso e do uso racional de medicamentos em crianças [Internet]. Brasília: Ministério da Saúde; 2017. [cited on Jun 13, 2020]. Available from: http://bvsms.saude.gov.br/ bvs/publicacoes/assistencia_farmaceutica_pediatria_brasil_ recomendacoes.pdf

32. Wang J, Avant D, Green D, Seo S, Fisher J, Mulberg AE, et al. A survey of neonatal pharmacokinetic and pharmacodynamic studies in pediatric drug development. Clin Pharmacol Ther. 2015;98(3):328-35. https://doi.org/10.1002/cpt.149 